alimentary tract, syphilis, diarrhœa and enteritis in children under two years, and accidents (including motor accidents) were the lowest reported in the last five years. The mortality from pneumonia was very low in 1939, the diminution being more than 33 per cent compared with 1938. The increases in the mortality from cancer, diabetes, cerebral hæmorrhage and heart disease must be attributed principally to the greater age of the population.

\section{Nature of the Long-period Variable Stars}

R. M. Scotr has an article on the long-pəriod variable stars in the Telescope of September-October, which provides a popular description of the type of star of which Mira is a prototype. The spectra of these stars reveal that they are cold enough to. contain molecules, and yet sufficiently hot to show the bright lines of hydrogen and ionized metals, and a brief explanation of the probable reason for this follows. Assuming that these stars are pulsating, we can picture a small core about the size of our sun surrounded by an atmosphere extending to a distance comparable with that of the earth from the sun. Viewed from a distance, one of these stars would present the appearance of a luminous fuzzy ball, deep in a hazy murk, and it is easy to imagine flames similar to solar prominences hovering deep in the smoky atmosphere near the luminous core. Then as the star approaches minimum the atmosphere would become darker and more clouded and the core a deeper red, the eruptions practically disappearing. It is possible that these red variables may be a link in the evolutionary chain, great numbers of stars starting their lives as red variables and then outgrowing their adolescent pulsations. On the other hand, redvariable pulsations may represent the palsy of stellar old age, though the former theory is the more popular of the two. At present this type of star presents a problem which can only be solved by much more investigation.

\section{William James (1842-1910)}

WrLliam James, the well-known psychologist and philosopher, was born in New York on January 11, 1842 , the son of the Swedenborgian theologian Henry James and brother of the novelist Henry James. He studied medicine at Harvard, where he qualified in 1869. He never engaged in practice, but after occupying the chairs of anatomy and physiology at Harvard, he devoted, himself entirely to psychology and philosophy. From 1889 until 1897 he was professor of psychology and from 1897 until 1907 professor of philosophy at his alma mater. During his last years he was chiefly occupied by the study of religion and metaphysics. He is perhaps best known for his championship of the doctrine of pragmatism inaugurated by C. S. Peirce of Cambridge, Miassachussets, according to which the value of any assertion is tested by its practical bearing upon human interests and purposes. He died on August 27, 1910. His principal publications were "Principles of Psychology" (1890), "Talks to Teachers on Psychology (1899), "Varieties of Religious Experience" (1902), and "Pragmatism" (1907). Numerous honours were conferred upon him at home and abroad, including membership of the National Academies of America, France, Italy, Prussia and Denmark, doctorate of letters at Padua and Durham, doctorate of laws at Harvard., Princeton and Edinburgh, and doctorate of science at Oxford and Geneva.

\section{Association of Special Libraries and Information Bureaux}

THE sixteenth annual general meeting of the Association of Special Libraries and Information Bureaux was held on December 13, 1941. The chair was taken by the president, Sir Harry Lindsay, director of the Imperial Institute, whose introductory remarks touched on the widening scope of the Association's activities, a subject that was further developed by Mr. E. J. Carter, the honorary" secretary, in his review of the year's work. The Association was fortunate enough to come through the winter's air-raids with only minor damage to the office; membership has remained steady and publications continued as usual. New opportunities for service arising from war conditions have been seized, among which was the investigation into the location and supply of scientific and technical periodicals now reaching the country from enemy and enemyoccupied territories, a survey carried out under the auspices of the Royal Society and the Rockefeller Foundation. Further details of the information thus compiled can be obtained on application to the ASLIB Oifice at 31, Museum Street, London, W.C.1. Other projects for bibliographical co-ordination are being considered.

\section{Medical History of the War}

An editorial board, under the chairmanship of the President of the Board of Education and composed of representatives of the Fighting Services, the Ministry of Health, the Department of Health for Scotland, the Committee of Imperial Defence and the Medical Research Council, has been set up by the War Cabinet to direct the preparation of a "Medical History of the War". The Board met recently and discussed the scope and planning of this undertaking, the value of which as a record of medical work during the War and of the War's contribution to medical science, will be appreciated. Sir Arthur MacNalty, until recently chief medical officer of the Ministry of Health, has been appointed editor-in-chief. The collection and classification of material for the "History" has now begun. The Editorial Board would be glad to receive copies of published articles, reports and other information from medical officers of health and medical practitioners which may be of use in assembling material for the medical historians; such data should be communicated to the Editor-in-Chief, Medical History of the War, Room 208, Caxton House West, Tothill Street, London, S.W.1.

\section{Announcements}

IT is announced by the New York correspondent of The Times that the Mount Palomar Observatory, in California, which is to house the 200 -in. telescope, will be closed on January 15 and will remain closed for the duration of the War.

Prof. Louis F. Fieser, professor of organic chemistry in Harvard University, has been awarded the Kathleen Berkan Judd one thousand dollar prize of the Memorial Hospital for the Treatment of Cancer and Allied Diseases, New York City, in recognition of his contributions to cancer research. Prof. Fieser's work in this connexion has dealt chiefly with chemistry and synthesis of carcinogenic compounds. 